\title{
The Possible Ameliorative Effect of Granulocyte Colony Stimulating Factor on Rotenone -Induced Changes in the Retinal Photoreceptors of Rats: Histological and Immunohistochemical Original Study Article
}

\author{
Samah Kandeel', Mohamed Balaha', Remon S. Estfanous ${ }^{3}$ \\ ${ }^{1}$ Department of Histology and Cell Biology, ${ }^{2}$ Department of Pharmacology, ${ }^{3}$ Department of \\ Anatomy and Embryology, Faculty of Medicine, Tanta University, Egypt.
}

\begin{abstract}
Introduction: Rotenone is an odorless isoflavone used as an insecticide, and piscicide. It is a potent inhibitor of the mitochondrial respiratory chain complex I leading to oxidative stress that ends with cell death. Granulocyte colony-stimulating factor (G-CSF) is a glycoprotein cytokine and a hematopoietic growth factor, produced by many cells. It promotes cell proliferation, survival, and mobilization. It also has anti-inflammatory and anti-apoptotic actions.

Aim: This study aimed to investigate the ameliorative effect of G-CSF in a rat model of rotenone-induced retinal photoreceptors' changes.

Materials and Methods: 25 male Wistar rats were used and were divided in to 3 groups; Control group; ROT group: by which rats received $30 \mathrm{mg} / \mathrm{kg} /$ day rotenone suspended in $0.25 \mathrm{ml} 0.5 \% \mathrm{CMC}$ orally beginning from 1 st day of the experiment till $28^{\text {th }}$ day; and G-CSF group: which was the rotenone group rats that further treated with $50 \mu \mathrm{g} / \mathrm{kg} / \mathrm{day} \mathrm{G}-\mathrm{CSF}$ in $0.1 \mathrm{ml} 5 \%$ dextrose subcutaneous for 15 days beginning from the $29^{\text {th }}$ day till the 43 rd day of the experiment.

Results: H \& E results of the ROT group showed outer \& inner segments with extensive structural damage, nuclear fragmentation, besides karyorrhexis, and karyolysis, together with vacuolations of the synaptic region. Also, significant increase of caspase-3 while, decrease of $\mathrm{N}$-cadherin immunohistochemical expression. The EM findings revealed extensive degenerative changes in the all segments of the photoreceptors besides significantly increased malondialdehyde levels.

Conclusion: G-CSF can ameliorates rotenone-induced degenerative structural changes in rat's retinal photoreceptors. This was through its anti-apoptotic and anti-inflammatory actions. So, G-CSF is a promising neuroprotective drug for retinal diseases and/or injuries.
\end{abstract}

Received: 16 June 2020, Accepted: 06 July 2020

Key Words: G-CSF, histology, immunohistochemistry, photoreceptors, rotenone.

Corresponding Author: Samah Kandeel, PhD, Department of Histology and Cell Biology, Faculty of Medicine, Tanta University, Egypt, Tel.: +20 1280912295, E-mail: Samah.kandeel@med.tanta.edu.eg

ISSN: $1110-0559$, Vol. 44, No.2

\section{INTRODUCTION}

The retina is situated in the eye where vision initiates. It converts light signals into the neurochemical signals, a process known as phototransduction so, it enables the brain to recognize the visual world ${ }^{[1]}$.

The photoreceptor layer includes the outer nuclear layer (ONL), layer of rods and cons (concerned with dimlight/nocturnal vision and the bright-light vision/visual acuity respectively), external limiting membrane, outer nuclear layer (ONL), and outer plexiform layer (OPL) $)^{[2]}$. The photoreceptors are located at the back of the retina and are attached to the retinal pigmented epithelium (RPE), which is responsible for the photoreceptors' survival ${ }^{[3]}$.

Retinal injuries, as well as, diseases can lead to loss of vision, and if it reaches the photoreceptors, cellular and visual loss ensues ${ }^{[4]}$. So, through understanding the mechanism of photoreceptor cell death during retinal injuries, a hope for a new strategy for treatment develops.

Rotenone (ROT) is an odorless isoflavone used as an insecticide, and piscicide (fish killer). It is also used in the form of powder for the treatment of scabies and head lice on humans, besides, parasitic mites on chickens, as well as pet animals ${ }^{[5]}$. It is considered as one of the pesticides frequently used in and around the home, as it is safe when correctly used. However, higher doses of it, will be toxic to humans, animals, as well as to fish ${ }^{[6]}$. Rotenone has been classified by WHO as a moderately hazardous Class II pesticide as it is involved in many suicidal attempts. It was proven to be neurotoxic in all tested species. In mammals, it causes vomiting, incoordination, muscle tremors, clonic convulsions, tachycardia, hypotension, and impaired 
myocardial contractility. In addition to Parkinson's diseaselike neuropathology ${ }^{[7,8]}$.

Rotenone is a potent inhibitor of the mitochondrial respiratory chain complex I (NADH-ubiquinone oxidoreductase) so, it interferes with the electron transport chain of mitochondria thru inhibition of the transfer of electrons from iron-sulfur centers in complex I to ubiquinone ${ }^{[9]}$. Consequently, oxidative stress, with the net result is damage to DNA and other components of the mitochondria. Besides, increased nitric oxide and malondialdehyde (MDA) levels that could end with cell death ${ }^{[10]}$. Moreover, rotenone is highly lipophilic with the ability to cross the blood-brain barrier rapidly. Presently, researchers used rotenone as an experimental drug that produces mitochondrial dysfunction in animal models ${ }^{[1]}$.

Granulocyte colony-stimulating factor (G-CSF) is a glycoprotein cytokine as well as a hematopoietic growth factor, produced by many cells like macrophages, and endothelium in response to inflammatory cytokines like tumor necrosis factor- $\alpha$ and interleukin- 6 . Its receptor is present in bone marrow precursor cells and it has the ability for promoting cell proliferation, survival, and mobilization ${ }^{[12]}$.

G-CSF has a role in the body's biological defense mechanisms; this is through stimulating the proliferation and differentiation of bone marrow neutrophil progenitors, to preserve mature as well as functional neutrophils and its release to the bloodstream ${ }^{[13]}$. It also enhances the neutrophils bactericidal activity, increases neutrophil halflife via prevention of its apoptosis, and down-regulates the inflammatory response through reducing monocytes and macrophages' cytokine production ${ }^{[14]}$. Additionally, G-CSF has anti-inflammatory and anti-apoptotic actions, besides cell proliferation and stem cell recruitment to the target sites $^{[15]}$. Moreover, it showed potent biological actions like reduction of inflammation, neurogenesis, apoptosis, treatment of heart degeneration, and reversal of the cognitive impairment in Alzheimer's disease ${ }^{[16]}$.

This study aims to investigate the possible ameliorative effect of G-CSF in a rat model of rotenone-induced retinal photoreceptors' changes. Also, with the hope that the results may induce valuable data for finding new treatments of retinal injuries and/or diseases. Therefore, histological, immunohistochemical, as well as biochemical studies were conducted.

\section{MATERIALS AND METHODS}

\section{Animals}

25 male Wistar rats weighing from 150 to $200 \mathrm{~g}$ (The animal House, Tanta University, Egypt) were obtained, then were housed in hygienic plastic cages at normal room temperature with 12 hours light and 12 hours darkness. Rats were allowed a free access to a standard laboratory diet with water ad libitum.
The experiment implemented was in consistent with the guideline for the care and use of the experimental animals with authorization of the University Institution Research Ethics Committee No. 34364/1/21.

\section{The experimental groups}

Rats were divided into 3 experimental groups:

I- Control group (15 rats): that was further subdivided into three subgroups ( 5 rats each); subgroup a: rats were left without any treatments throughout the duration of the experiment, subgroup b: rats received $0.25 \mathrm{ml} 0.5 \%$ carboxymethyl cellulose (CMC) (El Gomhuria Co., Egypt) orally by intragastric tube starting from the $1^{\text {st }}$ day of the experiment till $28^{\text {th }}$ day corresponding to the ROT

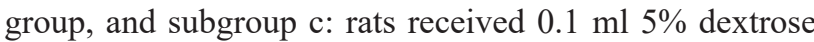
subcutaneous (SC) for 15 days beginning from the $29^{\text {th }}$ day till the $43^{\text {rd }}$ day of the experiment corresponding to the G-CSF group.

II- ROT group (5 rats): rats received $30 \mathrm{mg} / \mathrm{kg} /$ day rotenone (Sigma, St., Louis, MO, USA) suspended in 0.25 $\mathrm{ml} 0.5 \% \mathrm{CMC}$ orally through an intragastric tube beginning from $1^{\text {st }}$ day of the experiment till $28^{\text {th }}$ day.

III- G-CSF group (5): which was the rotenone group rats that treated with $50 \mu \mathrm{g} / \mathrm{kg} /$ day G-CSF (Roche Co., Basel, Switzerland) in $0.1 \mathrm{ml} \mathrm{5 \%}$ dextrose SC for 15 days beginning from the $29^{\text {th }}$ day till the $43^{\text {rd }}$ day of the experiment ${ }^{[17,18]}$

At the last day of the treatment; rats were anesthetized with i.p. injection of $50 \mathrm{mg} / \mathrm{kg}$ pentobarbital sodium, then the rats' eyes immediately enucleated, and washed with saline. At that time, the right eyes were taken and some of them immersed in $10 \%$ formalin buffered saline followed by embedding into paraffin wax then, $5 \mu \mathrm{m}$ sections (meridian at optic nerve level) obtained for light microscopic evaluation. While the others were fixed in $4 \%$ phosphate-buffered glutaraldehyde and were processed for ultrastructural examination. Additionally, retinas from the left eyes extracted in a dim red light at $4{ }^{\circ} \mathrm{C}$ and processed for estimation of malondialdehyde (MDA) levels in retinal tissue.

\section{Light microscopic examination}

\section{Haematoxylin \& Eosin (H\&E) stain}

Tissue sections were deparaffinized, then were hydrated and stained with hematoxylin and eosin. After that, dehydration, and clearance with xylol. Finally mounting in Canada balsam ${ }^{[19]}$

The photoreceptor layer thickness was measured $(\mu \mathrm{m})$; which an index of the retinal photoreceptor loss. Through the image-J program (Java. 1.6.0. 2013, USA) a line was made starting from the pigmented epithelial cell layer to the outer nuclear layer in $10 \mathrm{H} \& \mathrm{E}$ selected images (X 400) of each experimental group ${ }^{[20]}$. 


\section{Immunohistochemical processing for caspase-3 \& $N$-cadherin}

In accordance with Hirota et al. ${ }^{[21]}$ and Lin et al. ${ }^{[20],}$ sections were deparaffinized then were rehydrated in graded alcohol. Then, were placed in a buffer solution and were boiled for $5 \mathrm{~min}$ in a microwave oven (Kenmore, maximal power $800 \mathrm{~W}$; Sears, Hoffman Estates, IL, USA) for antigen retrieval. Sections then were allowed to cool down for $20 \mathrm{~min}$ at room temperature then were placed in $0.3 \%$ hydrogen peroxide/methanol for $20 \mathrm{~min}$ to inactivate endogenous hydrogen peroxidase activity. After that, a serum-free protein blocking solution was added to block the non-specific protein binding sites. Then, the addition of the primary antibody at $4{ }^{\circ} \mathrm{C}$; anti-caspase-3 (1:100) (Lab Vision/NeoMarkers, USA) and anti-N-cadherin antibodies (1:100) (Transduction Laboratories, Lexington, KY, USA). Sections then were washed by PBS buffer and incubated with biotinylated secondary antibody (Termo, Fremont, California, USA) 30 minutes at room temperature. Lastly, sections were counterstained with Mayer's hematoxylin after the addition of DAB, then dehydrated, cleared and mounted. Brownish granules observed in the cell cytoplasm indicated a caspase- 3 positive reaction. While, N-cadherin showed a positive membranous reaction. Moreover, negative control with no immunoreaction obtained through the staining of sections without the addition of the primary antibody.

The number of photoreceptor cells with positive caspase-3 immuno-histochemical reaction were assessed through counting the outer nuclear layer (ONL) in 10 randomly chosen fields of 10 sections of each experimental group. This was through an image analyzer (Leica Q 500, Japan) at a magnification of 1000 . Then, the photoreceptor number expressed per retinal section.

\section{Transmission electron microscopy procedure}

Sections were post-fixed in $1 \%$ osmium tetroxide for $2 \mathrm{~h}$ at room temperature after fixation in $4 \%$ glutaraldehyde. Then $1 \mathrm{~mm}^{3}$ piece section were obtained. After that, sections were dehydrated and embedded in epoxy resin. The ultrathin sections cut from 70 to $90 \mathrm{~nm}$ using the ultramicrotome (Leica, Austria), then loaded over 200 mesh copper grids. Followed by staining with uranyl acetate and lead citrate. Lastly, sections were examined and photographed using an electron microscope (JEOLJEM-100 SX, Japan) at the Electron Microscopy Unit, Faculty of Medicine, Tanta University ${ }^{[22]}$.

\section{Measurement of retinal tissue Malondialdehyde (MDA) level}

The malondialdehyde retinal concentrations evaluated by the following steps; first, retinal tissue were homogenized in $1 \mathrm{ml}$ of $0.1 \mathrm{mmol}$ Tris-HCL buffer $(\mathrm{pH}=7)$. Then, the homogenate was centrifuged at $5000 \mathrm{rpm}$ for 15 minutes at $4{ }^{\circ} \mathrm{C}$ and stored at $-30^{\circ} \mathrm{C}$. Finally, by using the kits for thiobarbituric acid assay (Sigma-Aldrich), retinal tissue MDA level was measured and expressed as $\mathrm{mmol} / \mathrm{mg}$ weight of retinal tissue ${ }^{[23]}$.

\section{Statistical analysis}

All data expressed as mean \pm SD. Variances among the experimental groups assessed using the two-tailed independent Student t-test, after evaluation of F- test. Significant results obtained when a $P$ value is $<0.05$.

\section{RESULTS}

\section{$H \&$ E results}

$\mathrm{H}$ \& E examination of the control group revealed retinal photoreceptors consisted of normally arranged rods and cones. Each consisted of outer segment attached to the retinal pigmented epithelium, an inner segment, a nuclear region with densely backed deeply stained nuclei besides the synaptic region. Additionally, the outer limiting membrane, is a series of junctional complexes between the photoreceptors and glial cells of the retina (Müller cells) (Figure 1A)

On seeing the ROT group; the outer segment showed extensive damage with broken-off and lost outer segments. As well as some of them were detached from the pigmented epithelium while others showed detachment from the inner segments. Moreover, the inner segments displayed damage in the form of spacing and vacuolations. While, the photoreceptor nuclei appeared with fragmentation, karyorrhexis, as well as karyolysis, besides wide space between them. As regards the synaptic region of the ROT group, multiple vacuolations were detected (Figure 1B).

In the G-CSF group, improvement of the previous findings of the retinal photoreceptors was noticed, and their histological structure was nearly normal (Figure 1C).

The photoreceptor layer thickness revealed a significant increase in the ROT group when compared to the control group, and significant decrease in the G-CSF in comparison to the ROT group (Figure 2).

\section{Caspase-3 immunohistochemical results}

Control group revealed faint positive caspase- 3 reaction in few photoreceptor cells in comparison to the intense reaction in the different segments of photoreceptors in the ROT group. Contrariwise, the G-CSF group expressed a marked reduction in the caspase- 3 immunohistochemical reaction being similar to the control group (Figure $3 \mathrm{~A}-\mathrm{D}$ ).

Considering caspase-3 positive photoreceptor number; there was a significant decrease in the G-CSF group when compared to the ROT group. While the latter expressed a significant increase in comparison to control (Figure 4).

\section{$\mathrm{N}$-Cadherin immunohistochemical results}

$\mathrm{N}$-cadherin expression of the control group represented positive reaction throughout all segments of photoreceptors. However, the most intense reaction was seen in the middle part; where the external limiting membrane is located (A junctional complex between Muller cells and photoreceptors at the level of the inner segment and outer nuclear region). 
Regarding the ROT group; the photoreceptor segments showed a faint $\mathrm{N}$-cadherin immunohistochemical reaction. Contrarily, the G-CSF group expressed a strong positive $\mathrm{N}$-cadherin immunohistochemical reaction (Figure 5A-D).

\section{Electron Microscopic (EM) results}

\section{Photoreceptor outer segments}

Photoreceptor outer segments of the control group were consisted of stacks of regularly arranged bi-membranous disks surrounded by plasma membranes that arranged perpendicular to the photoreceptor axis. Whereas, the ROT group revealed degenerative changes in the form of disorganization, discontinuity as well as vacuolations of the lamellar disks. In addition, distortion and displacement of the lamellar disc membranes was accompanied by protrusion of the plasma membrane. On the other hand, the G-CSF treated group showed improvements in the previous EM changes to give a picture similar to the control group (Figure 6 A-C).

\section{Photoreceptor inner segments}

The control group revealed elongated inner segments with round to oval mitochondria. The inner segments of the ROT group showed swollen degenerated mitochondria with destructed cristae. Oppositely, the G-CSF treated group displayed nearly normal inner segments with nearly normal mitochondria (Figure 7 A-C).

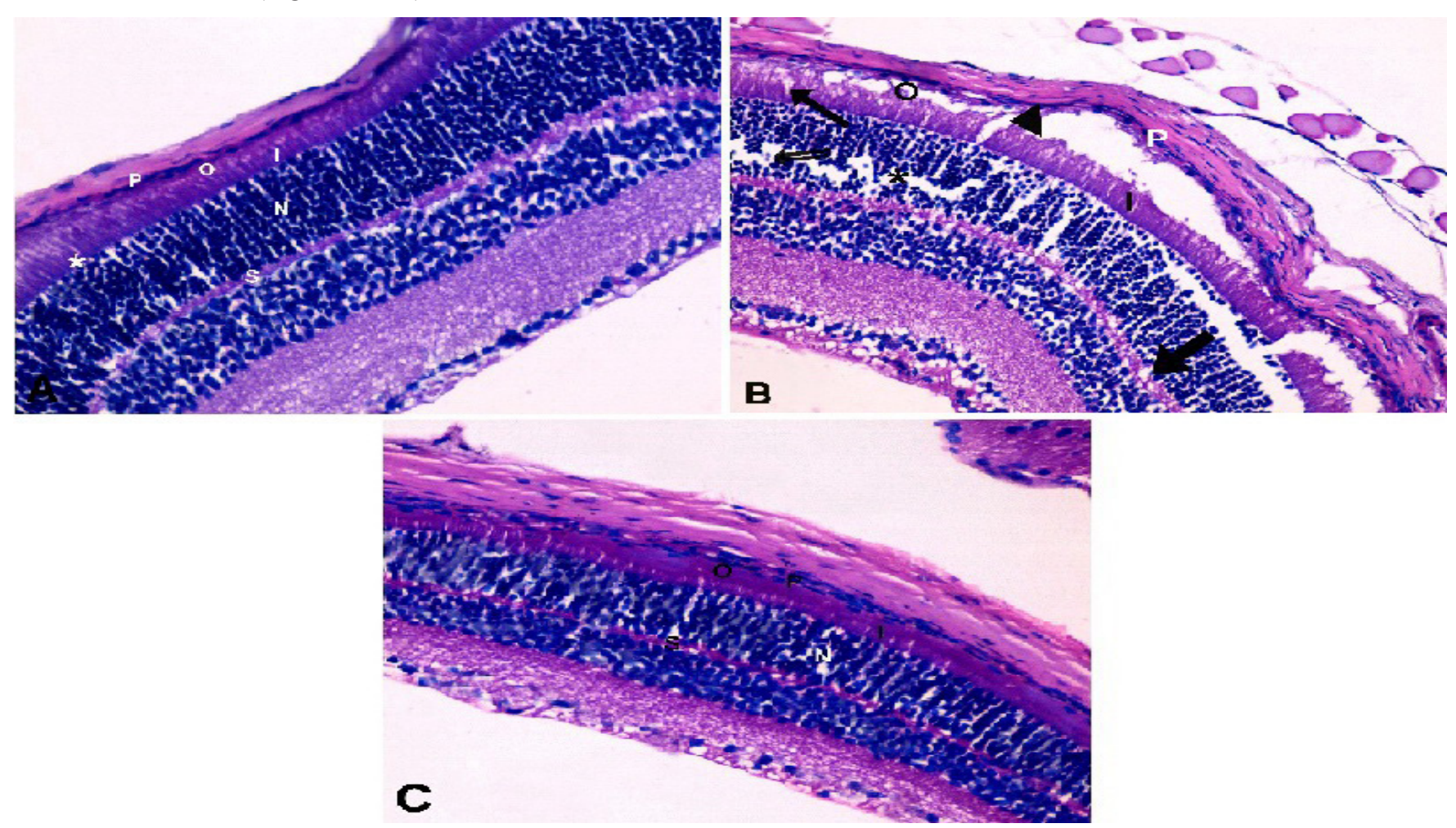

\section{Nuclei of the Photoreceptors}

The control group exhibited rounded nuclei with an eccentric nucleoli and finely dispersed chromatin. However, most of the nuclei of ROT group appeared hyperchromatic and pyknotic with clumped chromatin. While, others showed karyorrhexis and even disappearance (karyolysis). Oppositely, the G-CSF treated group showed an EM picture like control (Figure 8 A-C).

\section{Photoreceptor synaptic regions (External plexiform layer)}

The pre-synaptic region of the control group revealed many mitochondria with transverse cristae in addition to synaptic vesicles. In the ROT group, markedly swollen degenerated mitochondria with destructed cristae were seen. Besides, fused mitochondria to form large degenerated ones. Regarding the G-CSF treated group; the synaptic region showed nearly normal synaptic EM structure (Figure 9 A-C).

\section{MDA levels in retinal tissue}

MDA level was significantly increased in the ROT group when compared to the control group. While in the G-CSF treated group; a significant decrease was encountered (Figure 10).

Fig. 1: A) A Control show outer segments of rods and cones $(\mathrm{O})$ attached to the retinal pigmented epithelium (P), inner segment (I), and nuclear region with densely backed deeply stained nuclei $(\mathrm{N})$ and synaptic region $(\mathrm{S})$. Outer limiting membrane is at the level between inner segments and outer nuclear layer $(*)$. B) Rotenone group show broken-off and lost outer segments $(\mathrm{O})$ with detachment of some of them from the pigmented epithelium (P) and from inner segments (I), spacing $(\longrightarrow)$ and vacuolations (thin arrow) of the inner segments, karyorrhexis of the photoreceptor nuclei (double arrow) with marked spacing $(*)$ and vacuolations of the synaptic region (thick arrow). C) G-CSF treated group show normal histological structure with outer segment (O) attached to the retinal pigmented epithelium (P), inner segment (I) nuclear (N) and synaptic region (S). (H\&E X 400). 


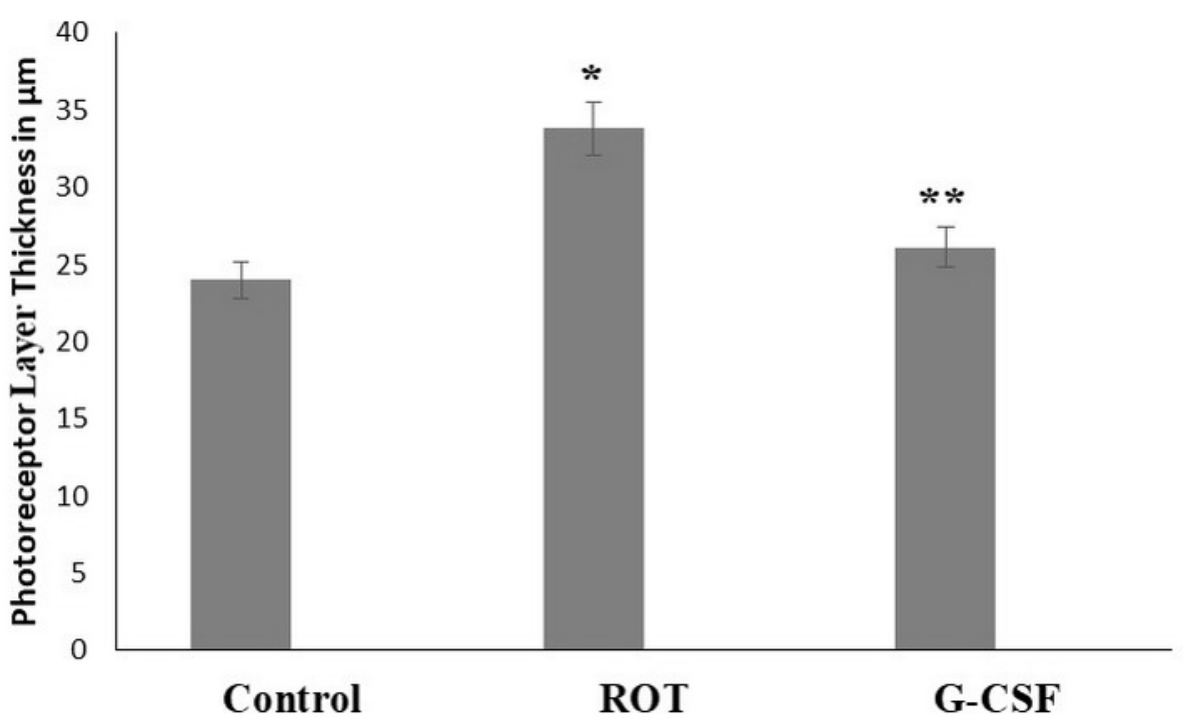

Fig. 2: The mean values of the thickness of the retinal photoreceptors. $*$ ROT; $P<0.05$ (Rotenone group in comparison to control), and $* *$ G-CSF; $P<0.05$ (Rotenone \& G-CSF group in comparison to the rotenone group).
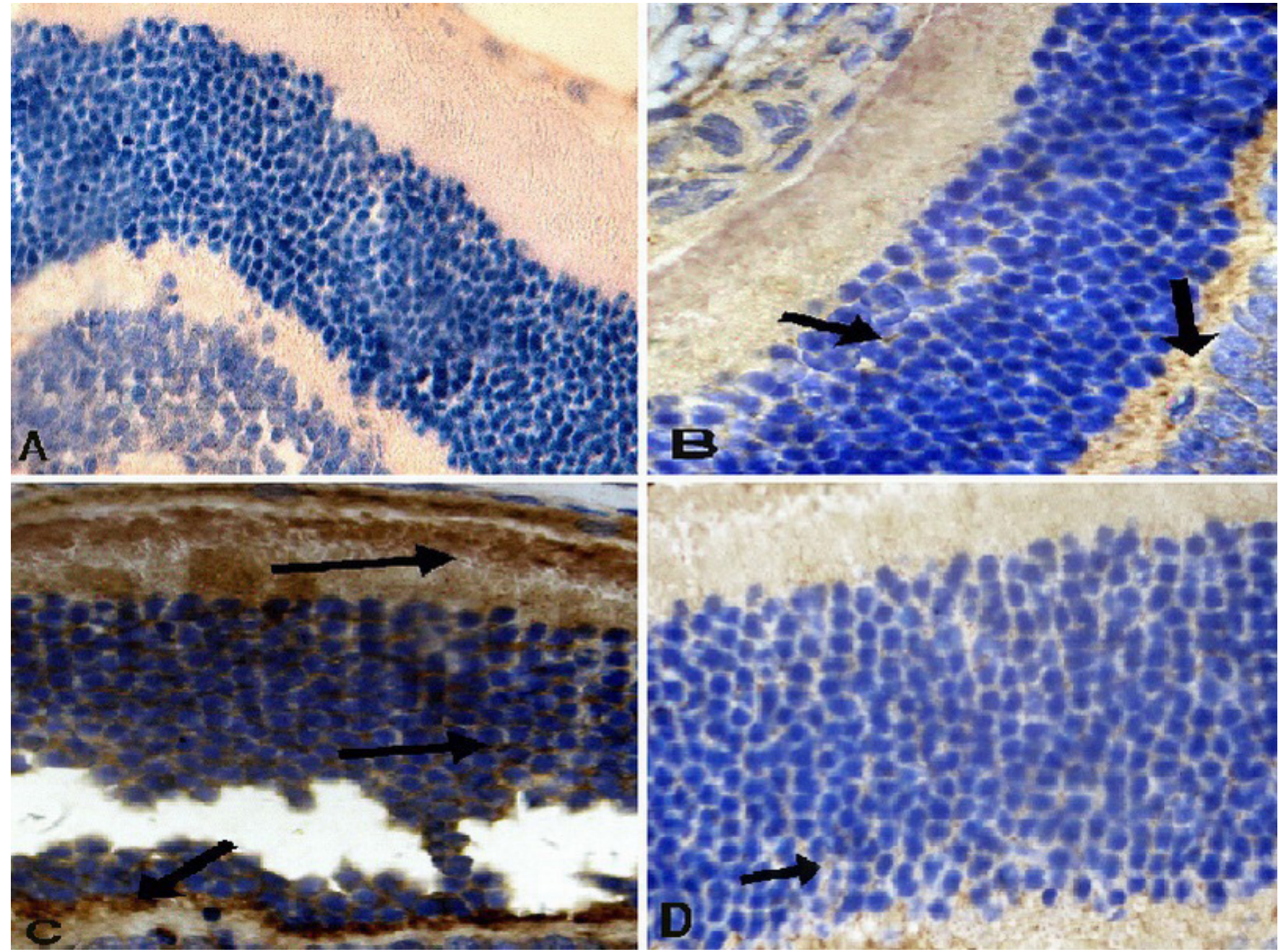

Fig. 3: A) Negative control show no caspase-3 immunohistochemical reaction. B) Control group show positive caspase-3 reaction in few photoreceptor cells $(\rightarrow)$. C) Rotenone group with an intense caspase-3 reaction in the different segments of rods and cones $(\rightarrow)$. D) G-CSF treated group show faint positive caspase-3 reaction in few photoreceptor cells $(\rightarrow)$. (Caspase- 3 immunohistochemistry X 1000) 


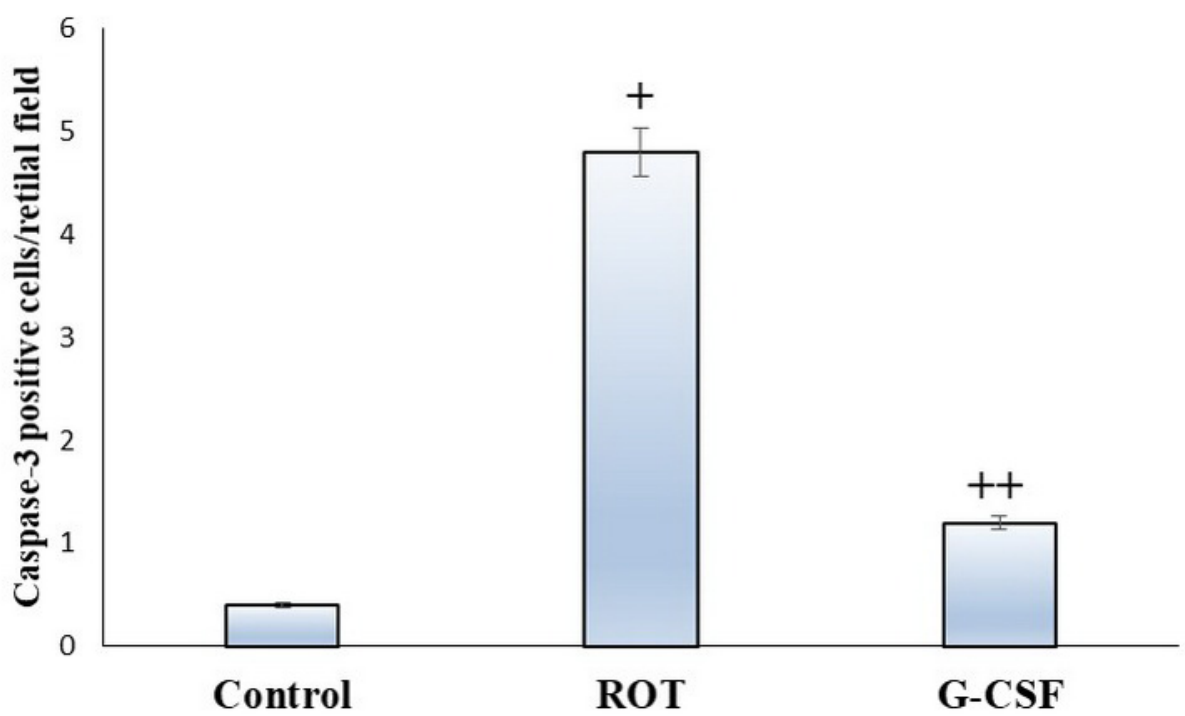

Fig. 4: Number of Caspase- 3 positive staining photoreceptor cells/ retinal field expressed as means \pm SD. + ROT; $P<0.05$ (Rotenone group in comparison to control), and $++\mathrm{G}-\mathrm{CSF} ; P<0.05$ (Rotenone \& G-CSF group in comparison to the rotenone group).
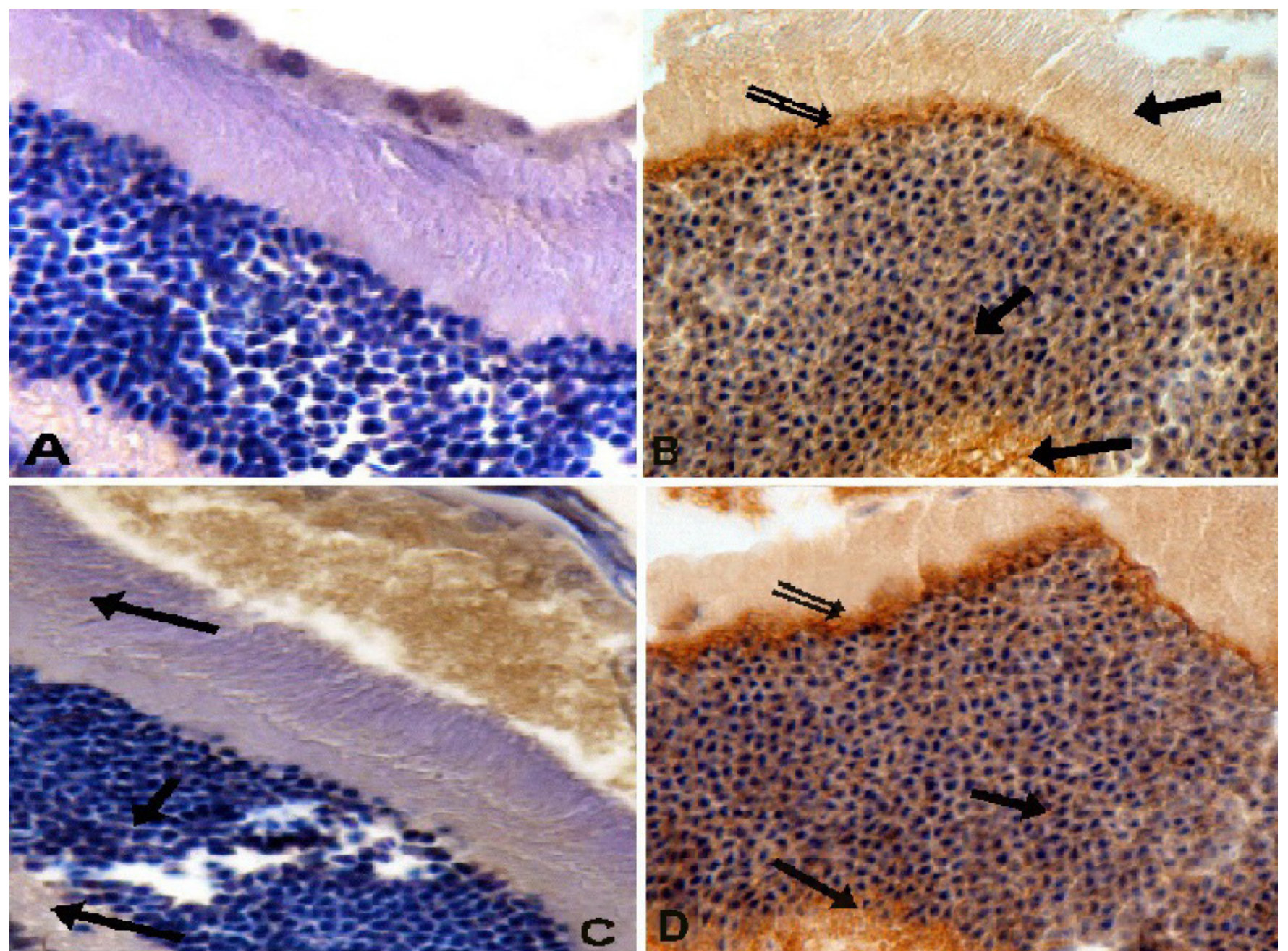

Fig. 5: A) Negative control show negative N-cadherin immunohistochemical reaction. B) Control group show positive N- cadherin reactions throughout all segments of photoreceptors $(\rightarrow$ ) with the most intense reaction seen at the level of the external limiting membrane (double arrow). C) Rotenone group with Faint N- cadherin reaction in the different segments of rods and cones $(\rightarrow)$. D) G-CSF treated group show strong N- cadherin reaction $(\rightarrow)$ especially at the external limiting membrane (double arrow). (N- Cadherin immunohistochemistry X 1000). 

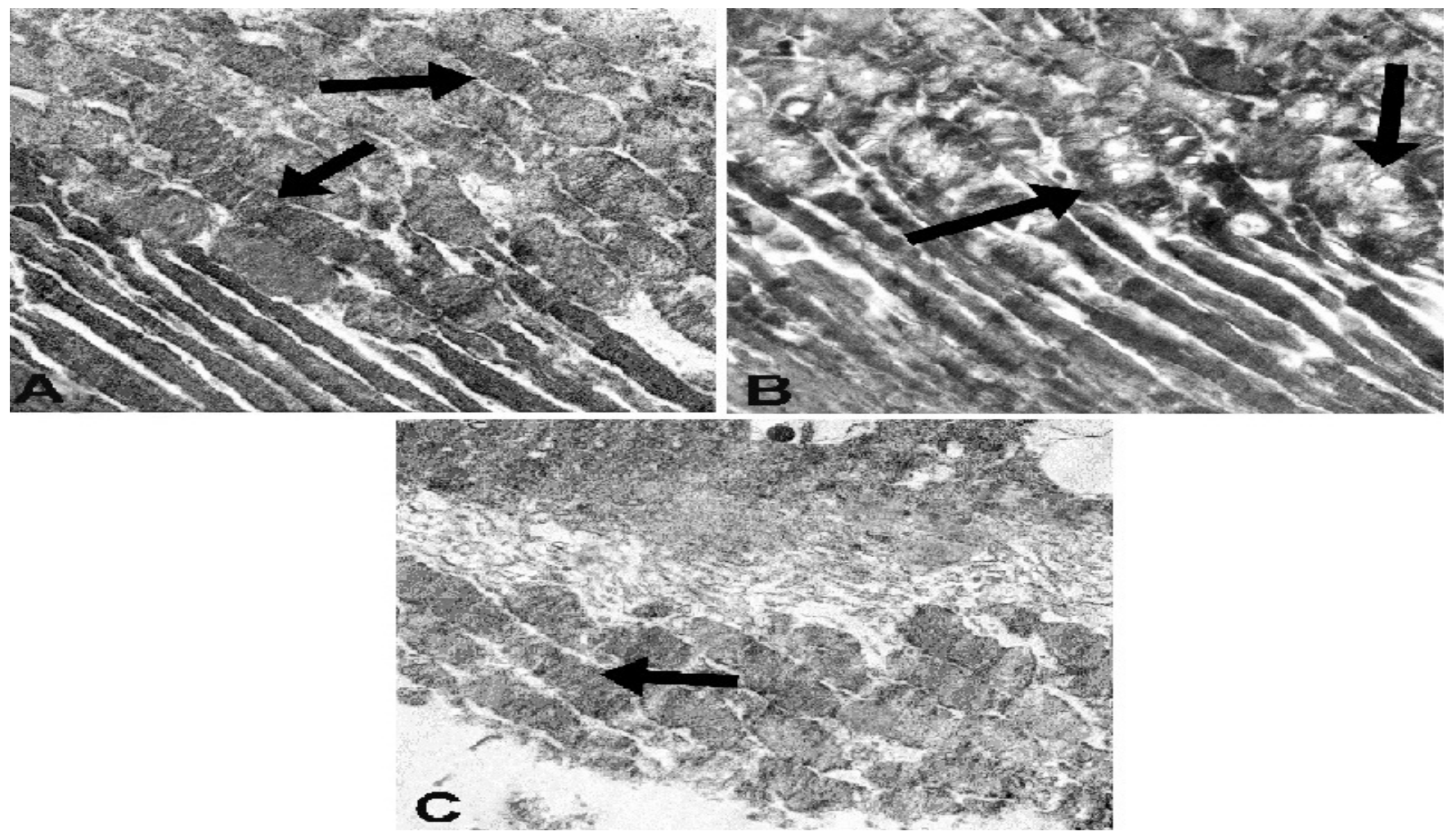

Fig. 6: EM changes of the photoreceptor outer segments X 2000. A) Control group show stacks of regularly arranged bi-membranous disks surrounded by plasma membranes that arranged perpendicular to the photoreceptor axis $(\rightarrow)$. B: Rotenone group show disorganization, vacuolations, and displacement of the lamellar disc membranes with protrusion of the plasma membrane $(\rightarrow)$. C: G-CSF treated group show stacks of regularly arranged bi-membranous disks surrounded by plasma membranes $(\rightarrow)$.
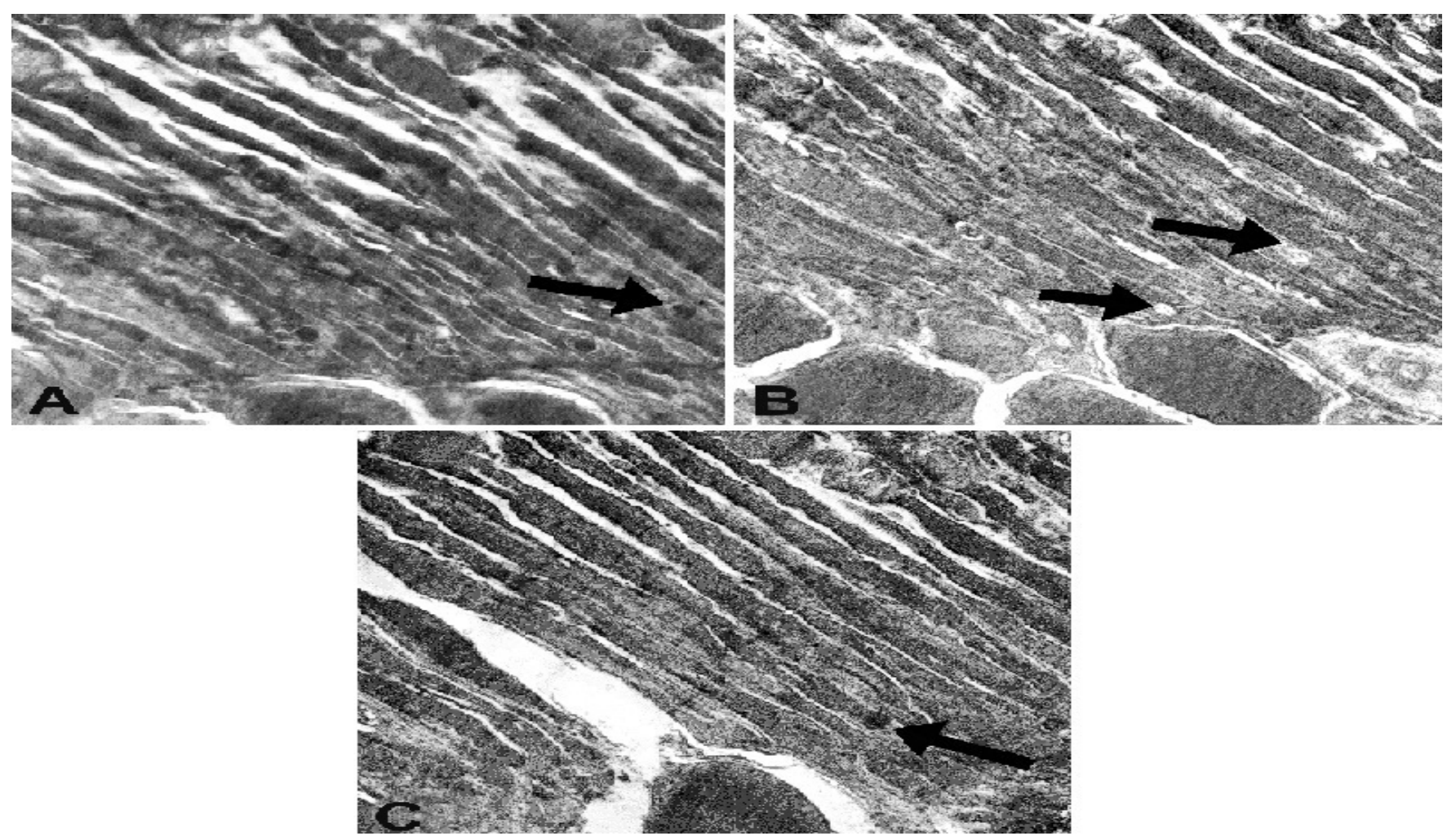

Fig. 7: EM changes of the photoreceptor inner segments X 2000. A) Control group reveal elongated inner segments contains round to oval mitochondria $(\rightarrow)$ B) Rotenone group show swollen degenerated mitochondria with destructed cristae $(\rightarrow)$. C) G-CSF treated group show nearly normal inner segments with rounded to oval mitochondria $(\rightarrow)$. 

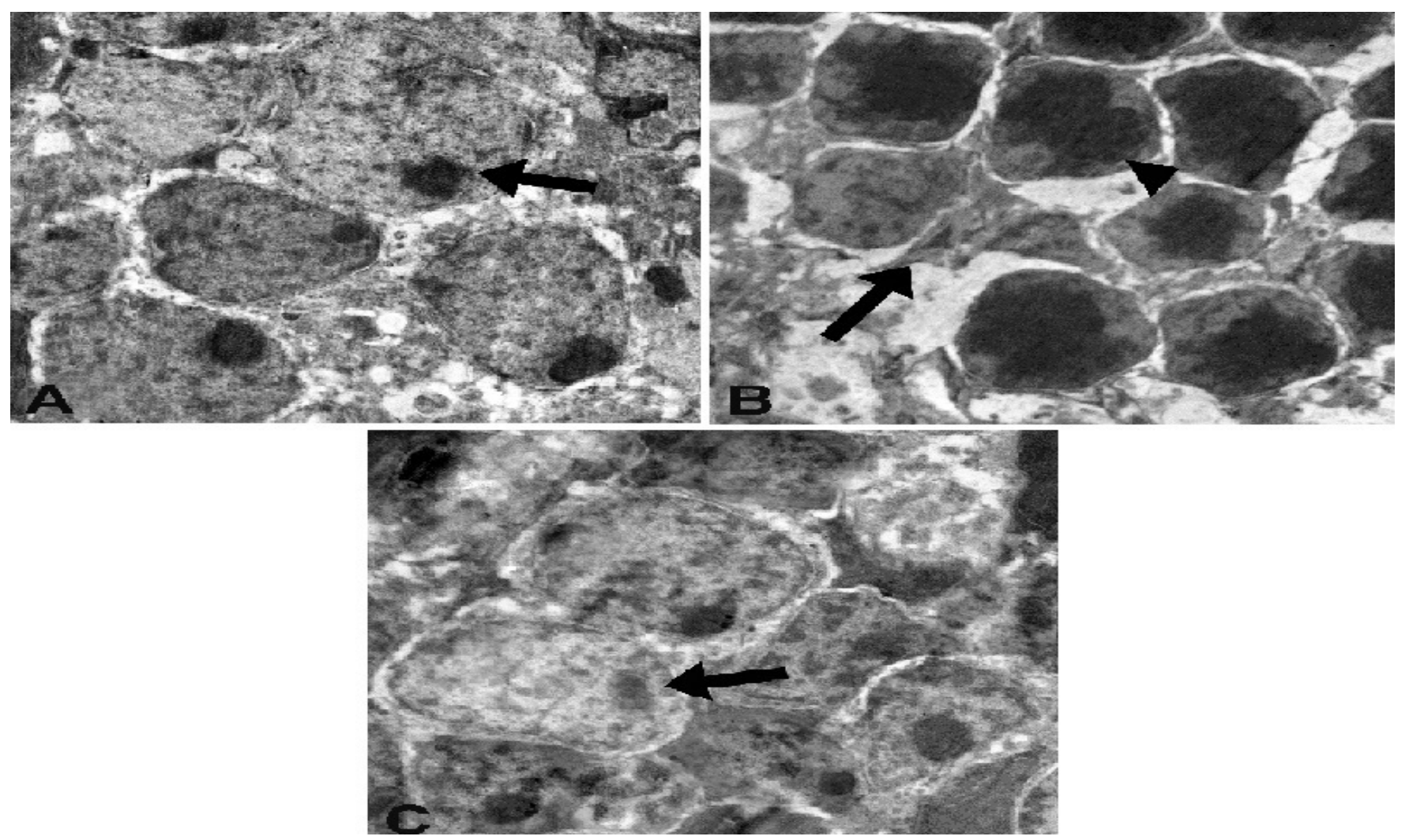

Fig. 8: EM changes of the nuclei of the photoreceptors X 2000. A) Control group exhibit rounded nuclei with eccentric nucleoli and fine dispersed chromatin $(\rightarrow)$. B) Rotenone group show hyperchromatic and pyknotic nuclei with clumped chromatin $(\downarrow)$ while others showed karyorrhexis and even disappearance $(\rightarrow)$. C) G-CSF treated group show rounded nuclei with an eccentric nucleoli and fine dispersed chromatin $(\rightarrow)$.
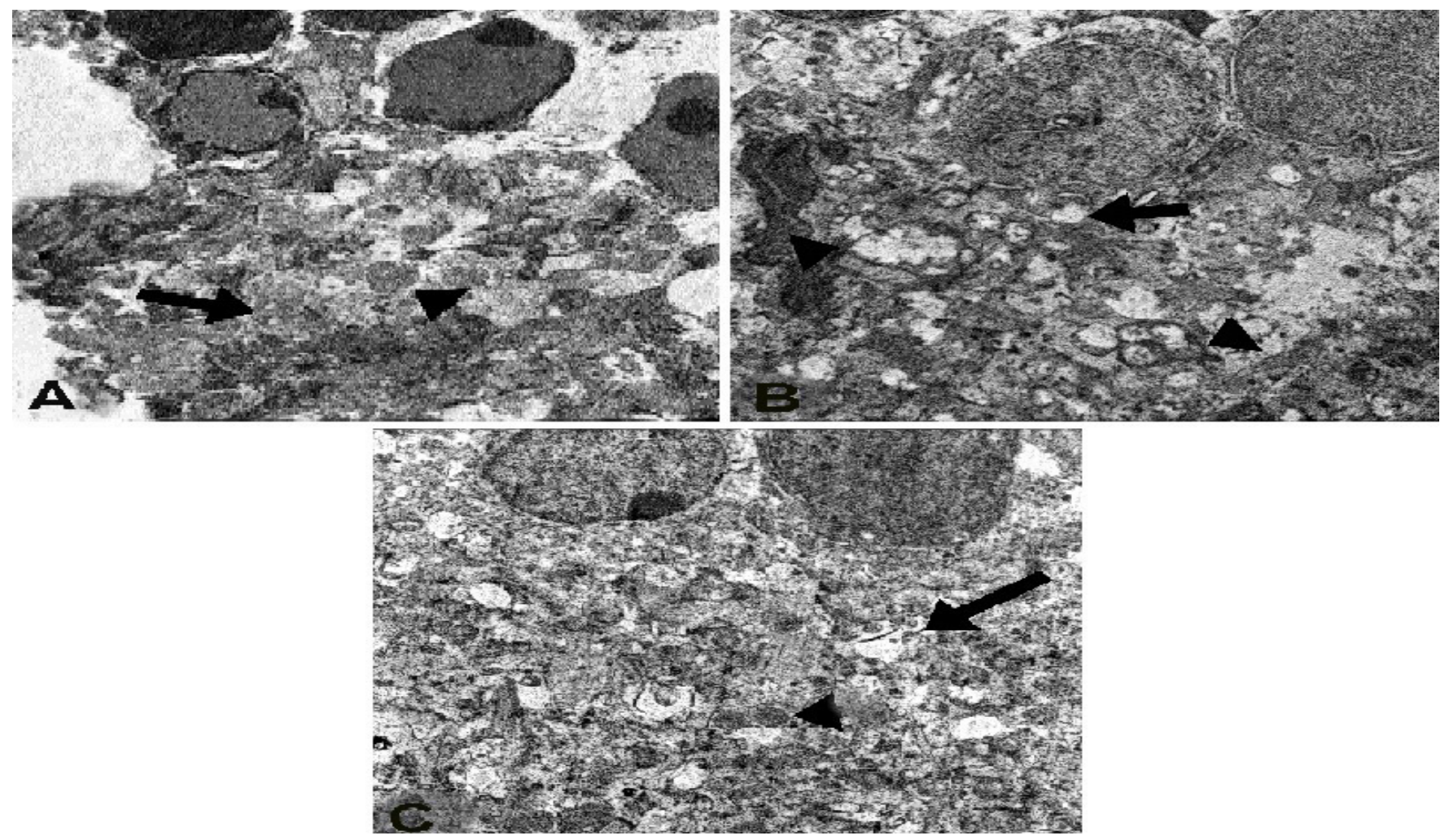

Fig. 9: EM changes of the photoreceptor synaptic region (External plexiform layer) X 2000. A) Control group reveal many mitochondria with transverse cristae $(\rightarrow)$ and synaptic vesicles $(\rightarrow)$. B) Rotenone group show markedly swollen degenerated mitochondria with destructed cristae $(\rightarrow)$, and fused mitochondria to form large degenerated ones $(\bullet)$. C) G-CSF treated group show a synaptic region with mitochondria $(\bullet)$ and synaptic vesicles $(\rightarrow)$. 


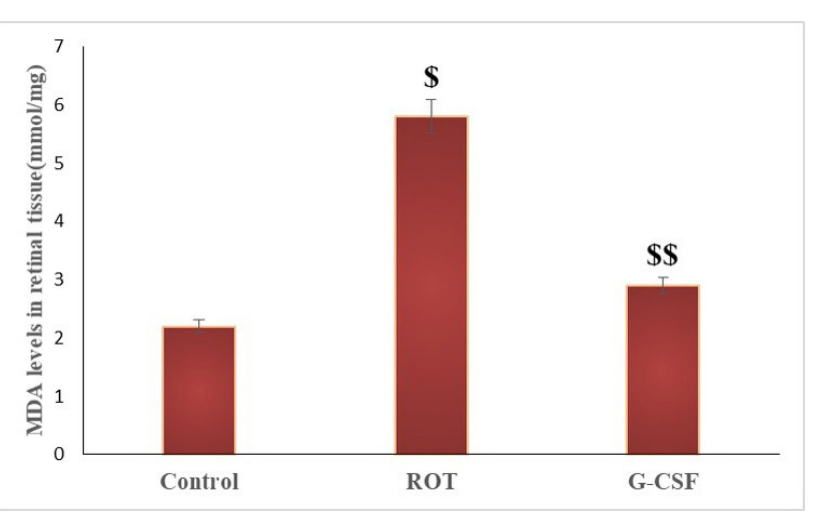

Fig. 10: MDA levels of the retinal tissue. Data expressed as means \pm SD. \$ Rot; $P<0.05$ (Rotenone group in comparison to control), and $\$ \$$ G-CSF; $P<0.05$ (Rotenone \& G-CSF group in comparison to the rotenone group).

\section{DISCUSSION}

Retinal injuries can lead to progressive visual loss because of photoreceptor cell affection that may end by their death. Photoreceptors are extremely sensitive to different toxic substances and because they are considered non-dividing cells, their loss leads to an irreversible visual $\operatorname{loss}^{[24]}$.

Chemicals are known to cause retinal toxicity, among them is rotenone, an insecticide experimentally harmful to the organs and induce cellular metabolic dysfunction ${ }^{[6]}$. In this light, rotenone-induced retinal photoreceptor changes in rats is a model used to detect the possible causes of photoreceptor cell death. So, new treatment strategies may be discovered to prevent photoreceptor loss, consequently, preserving the eye vision.

The present study showed marked degenerative changes in photoreceptors induced by rotenone. Reviewing the H\&E stained sections; broken-off and lost outer segments was seen besides detachment from the pigmented epithelium as well as from the inner segments. Moreover, the inner segments exhibited spacing and vacuolations with fragmented nuclei and karyorrhexis. While the synaptic region showed multiple vacuolations. These changes were accompanied with a significant increase in caspase-3 as well as decreased expression of N-Cadherin in immunohistochemical staining preparations. Also, through the EM examination of the rotenone group, the photoreceptors showed marked EM structural changes of its different segments. Moreover, the MDA level in retinal tissue was significantly elevated.

Photoreceptor outer segments are specialized sensory cilia with hundreds of membrane discs containing phototransduction proteins and are renewed by opposing processes of disk morphogenesis and shedding. Disk renewal requires protein and lipid synthesis in the inner segment of photoreceptors, a substructure located beneath the outer segment ${ }^{[25]}$

The broken-off and lost outer segments of photoreceptors besides detachment from the pigmented epithelium as well as from the inner segments seen in H\&E stained sections' can be explained by the fact that rotenone inhibits mitochondrial respiratory chain complex ${ }^{[25]}$; the source of ATP generation and energy demand. Consequently, ATP production reduced with the increase of reactive oxygen species generation (ROS) inducing oxidative stress. The latter leads to mitochondrial protein misfolding, damage to the mitochondrial DNA. In addition to lipid peroxidation with damage to the membrane lipids, proteins, that leads to elevation of the MDA levels and finally cell degeneration ${ }^{[26]}$. Also, rotenone is a lipophilic toxic agent that can easily cross the biological membranes leading to its damage ${ }^{[5]}$.

Moreover, the disturbing mitochondrial function induced by rotenone initiates disturbance of the cellular calcium homeostasis with subsequent disturbed cellular metabolism leading to vacuolations and edema ${ }^{[25]}$.

The present research showed a significant increase in caspase-3 immunohistochemical reaction indicating photoreceptors apoptosis. Which is barrel to the findings of Han et al ${ }^{[27]}$ during their study on the rotenone effect on cultured rat retina.

Apoptosis, is a programmed cell death characterized by the activation of caspases. Caspase- 3 is an activated death protease known as "executioner caspase". Its release is triggered via the mitochondrial pathway with the activation of caspase-9. Lee et al. ${ }^{[28]}$ showed that rotenone-induced apoptosis through the mitochondrial release of cytochrome c, ROS, and caspase-3 activation. Moreover, rotenone can prevent cell microtubule assembly through the prevention of tubulin-binding, resulting in the arrest of mitosis, hence, inhibition of cell proliferation ${ }^{[5]}$.

Nuclear changes were observed in the present study. These were in the form of fragmentation, pyknosis, karyorrhexis and even disappearance (karyolysis). It was known that rotenone-induced cell toxicity and death thru oxidative stress and ATP reduction ${ }^{[27]}$. Additionally, rotenone increased the intracellular calcium levels which will initiates the release of calpains from the endoplasmic reticulum (ER); then translocates to the nucleus with chromatin condensation and DNA fragmentation. Consequently, protein misfolding as well as expression of ER-localized chaperones and pro-apoptotic transcription factors. So, leading the cell towards apoptosis expressed by its clumped chromatin and nuclear fragmentation ${ }^{[27 ; 29]}$.

$\mathrm{N}$-cadherin is a transmembrane glycoprotein mediates calcium-dependent cell-cell contact site and expressed in neural cells. It is also expressed in the retinal pigmented cells as well as photoreceptor segments ${ }^{[30]}$. It has a role in different cell processes, like cell proliferation \& differentiation, and apoptosis. N-cadherin possess intracellular \& extracellular domain linked together by $\mathrm{Ca}_{2}{ }^{+}$binding linker region that gives rigidity to the molecule of $\mathrm{N}$-cadherin ${ }^{[31]}$.

The present research revealed decreased $\mathrm{N}$-cadherin immunohistochemical expression. It is in agreement with 
Han et al. ${ }^{[27]}$ who documented the effect of rotenone on the cellular calcium homeostasis disrupting the connection between the intracellular from the extracellular domain of $\mathrm{N}$-cadherin.

The degenerative changes seen during the EM examination were in the form of outer segment disorganizations, and vacuolations of the lamellar disks. These were accompanied by protrusion of the plasma membrane, inner segment swellings with swollen degenerated mitochondria. Moreover, there were nuclei with clumped chromatin beside karyorrhexis and markedly swollen degenerated mitochondria of the synaptic region. The previous EM structural changes come in compatible with Normando et al.$^{[32]}$ who proved the presence of retinal cell degenerations in a rat model of Parkinson's disease.

Moreover, these EM changes can be explained by the fact that rotenone-induced mitochondrial degenerations with subsequent oxidative stress which is also in agreement with Kohara et al. ${ }^{[33]}$ who documented that rotenoneinduced retinal degeneration through oxidative stress.

Oxidative stress lead to damage to the cell organelles as well as its components like lipids, proteins, and DNA. It is also associated with lipid peroxidation with subsequent degenerative changes of the mitochondrial wall as well as the cell membrane ${ }^{[34]}$. Also, rotenone-induced mitochondrial complex I inhibition leading to the inhibition of the mitochondrial respiratory chain. This could elevates the release of mitochondrial ROS, consequently, cell apoptosis $^{[5]}$.

Granulocyte colony-stimulating factor (G-CSF) is a hematopoietic growth factor regulates mobilization, proliferation, and differentiation of the bone marrow stem cells. It is used in the treatment of cancers, autoimmune diseases, and degenerative diseases due to its protective effect ${ }^{[15]}$. It is also has anti-inflammatory and anti-apoptotic effects. Additionally, the presence of G-CSF receptors in the retina makes the treatment with G-CSF beneficial as a neuroprotective agent ${ }^{[35]}$.

The present research revealed the ameliorative effect of G-CSF on rotenone-induced photoreceptor changes which were detected by light, immunohistochemical, EM examination and a significant decrease in the retinal tissue MDA levels. This comes in agreement with Oishi et al ${ }^{\left[{ }^{[36]}\right.}$ who established the protective effect of G-CSF on the retinal photoreceptors in a rat model for retinal damage as a result of exposure to light. Also, El-Esawy et al. ${ }^{[18]}$ proved the neuroprotective effect of G-CSF in different neurodegenerative disease models, like Parkinson's disease.

The anti-apoptotic effect of G-CSF is through the inhibition of the mitochondrial-dependent caspase-3. This is via the inhibition of Bax translocation and/or increased levels of anti-apoptotic factors like bcl-2, so, inhibits photoreceptor apoptosis. Moreover, it inhibits calpains activation with decreased intracellular $\mathrm{Ca}^{2+}$ release during apoptosis. Consequently, inhibition of activation of the pro-apoptotic factors preventing cell degradation as well as cell death ${ }^{[37]}$.

Another mechanism for G-CSF protection is through its anti-inflammatory effect. This is by the reduced release of IL-4, TGF- $\beta 1$, interferon- ${ }^{\gamma}$, and TNF- $\alpha$. Following that is the reduction of T-cell immigration to the injury site. Moreover, it allows mobilization of the hematopoietic stem cells from the bone marrow into peripheral blood and then its participation in retinal angiogenesis. So, leading to retinal regeneration and photoreceptor survival ${ }^{[36]}$.

\section{CONCLUSION}

The data and results of the present research indicated the presence of different degenerative structural changes of the photoreceptors induced by rotenone. This could be through the generation of ROS as well as caspase-3 activation. Additionally, G-CSF ameliorated these changes by its anti-apoptotic and anti-inflammatory actions. Also, this study endorses that G-CSF is a promising neuroprotective drugs for retinal diseases and/or injuries. Meanwhile, more studies are required to approve the effectiveness of G-CSF alone or in combinations with additional hematopoietic cytokines.

\section{CONFLICT OF INTERESTS}

There are no Conflicts of Interest.

\section{REFERENCES}

1. Lukowski SW, Lo CY, Sharov AA, Nguyen Q, Fang L, Hung SS, Zhu L, Zhang T, Grünert U and Nguyen $\mathrm{T}$ : A single-cell transcriptome atlas of the adult human retina. The EMBO journal. (2019) 38(18).

2. Wensel TG, Zhang Z, Anastassov IA, Gilliam JC, He F, Schmid MF and Robichaux MA: Structural and molecular bases of rod photoreceptor morphogenesis and disease. Prog Retin Eye Res. (2016) 55: 32-51.

3. Molday RS and Moritz OL: Photoreceptors at a glance. J Cell Sci. (2015) 128(22): 4039-4045.

4. Hoon M, Okawa H, Della Santina L and Wong RO: Functional architecture of the retina: development and disease. Prog Retin Eye Res. (2014) 42: 44-84.

5. Heinz S, Freyberger A, Lawrenz B, Schladt L, Schmuck $\mathrm{G}$ and Ellinger-Ziegelbauer $\mathrm{H}$ : Mechanistic investigations of the mitochondrial complex I inhibitor rotenone in the context of pharmacological and safety evaluation. Sci Rep. (2017) 7: 45465.

6. Gupta RC, Mukherjee IRM, Malik JK, Doss RB, Dettbarn W-D and Milatovic D. Insecticides. Biomarkers in toxicology. $2^{\text {nd }}$ ed., Acadmy Press. Elsevier. (2019)pp: 455-475.

7. Xiong N, Long X, Xiong J, Jia M, Chen C, Huang J, Ghoorah D, Kong X, Lin Z and Wang T: Mitochondrial complex I inhibitor rotenone-induced toxicity and its potential mechanisms in Parkinson's disease models. Crit Rev Toxicol. (2012) 42(7): 613-632. 
8. Chiaradia E, Renzone G, Scaloni A, Caputo M, Costanzi E, Gambelunghe A, Muzi G, Avellini L, Emiliani $\mathrm{C}$ and Buratta $\mathrm{S}$ : Protein carbonylation in dopaminergic cells exposed to rotenone. Toxicol Lett. (2019) 309: 20-32.

9. Onukwufor JO, Berry BJ and Wojtovich AP: Physiologic Implications of Reactive Oxygen Species Production by Mitochondrial Complex I Reverse Electron Transport. Antioxidants. (2019) 8(8): 285.

10. Callizot N, Combes M, Henriques A and Poindron P: Necrosis, apoptosis, necroptosis, three modes of action of dopaminergic neuron neurotoxins. PLoS ONE. (2019) 14(4): e0215277.

11. Dorman D. Extrapyramidal system neurotoxicity: animal models. Handbook of clinical neurology. Vol. 131, Elsevier. (2015)pp: 207-223.

12. Ahuja CS, Cadotte DW and Fehlings M. Spinal cord injury. Principles of Neurological Surgery. Elsevier. (2018)pp: 518-531. e513.

13. Takei $\mathrm{Y}$, Ando $\mathrm{H}$ and Tsutsui $\mathrm{K}$ : Handbook of hormones: comparative endocrinology for basic and clinical research. $1^{\text {st }}$ ed., Academic Press. Elsevier. (2016)pp: 250-280.

14. Culnan D, Capek KD, Voigt C and Muthumalaiappan K. Hematology, Hemostasis, Thromboprophylaxis, and Transfusion Medicine in Burn Patients. Total Burn Care. $5^{\text {th }}$ ed., Elsevier. (2018)pp: 236-247. e236.

15. Sameni HR, Seiri M, Safari M, Amjad MHT, Khanmohammadi $\mathrm{N}$ and Zarbakhsh $\mathrm{S}$ : Bone Marrow Stromal Cells with the Granulocyte Colony-Stimulating Factor in the Management of Chemotherapy-Induced Ovarian Failure in a Rat Model. Iran J Med Sci. (2019) 44(2): 135.

16. Lee SW, Kang NH and Choi JW: Functional Secretion of Granulocyte Colony Stimulating Factor in Bacillus subtilis and Its Thermogenic Activity in Brown Adipocytes. Biotechnol Bioproc E. (2019) 24(2): 298-307.

17. Liao C-H, Chen S-Y, Kuo J-S and Pang C-Y: Reduction of motor disorder in 6-OHDA-induced severe parkinsonism rats by post treatment with granulocyte-colony stimulating factor. Chin J Physiol. (2013) 56(3): 147-154

18. El-Esawy R, Balaha M, Kandeel S, Hadya S and El-Rahman M-NA: Filgrastim (G-CSF) ameliorates Parkinsonism 1-dopa therapy's drawbacks in mice. Basal Ganglia. (2018) 13: 17-26.

19. Suvarna KS, Layton C and Bancroft JD: Bancroft's Theory and Practice of Histological Techniques. $8^{\text {th }}$ ed., Elsevier. (2019)pp: 40- 126.

20. Lin J-L, Wang Y-D, Ma Y, Zhong C-M, Zhu M-R, Chen W-P and Lin B-Q: Protective effects of naringenin eye drops on $\mathrm{N}$-methyl-N-nitrosourea-induced photoreceptor cell death in rats. Int J Ophthalmol. (2014) 7(3): 391.
21. Hirota K, Kaneko Y, Matsumoto G and Hanyu Y: Cadherin expression during retinal regeneration in the adult newt. Zoolog Sci. (2001) 18(2): 145-150.

22. Bozzola JJ and Russell LD: Electron microscopy: principles and techniques for biologists. $2^{\text {nd }}$ ed., Jones \& Bartlett Publishing. (1999)pp: 148-156.

23. Baksheeva V, Tiulina V, Tikhomirova N, Gancharova O, Komarov S, Philippov P, Zamyatnin A, Senin I and Zernii E: Suppression of Light-Induced Oxidative Stress in the Retina by Mitochondria-Targeted Antioxidant. Antioxidants. (2019) 8(1): 3-11.

24. Sweigard JH, Matsumoto H, Smith KE, Kim LA, Paschalis EI, Okonuki Y, Castillejos A, Kataoka K, Hasegawa E and Yanai R: Inhibition of the alternative complement pathway preserves photoreceptors after retinal injury. Sci Transl Med. (2015) 7(297): 297ra116-297ra116.

25. Mekala NK, Kurdys J, Depuydt MM, Vazquez EJ and Rosca MG: Apoptosis inducing factor deficiency causes retinal photoreceptor degeneration. The protective role of the redox compound methylene blue. Redox biology. (2019) 20: 107-117.

26. Hytti M, Korhonen E, Hyttinen JM, Roehrich H, Kaarniranta K, Ferrington DA and Kauppinen A: Antimycin A-Induced Mitochondrial Damage Causes Human RPE Cell Death despite Activation of Autophagy. Oxid Med Cell Longev. (2019) 2019.

27. Han G, Casson RJ, Chidlow G and Wood JP: The mitochondrial complex I inhibitor rotenone induces endoplasmic reticulum stress and activation of GSK-3 $\beta$ in cultured rat retinal cells. Invest Ophthalmol Visual Sci. (2014) 55(9): 5616-5628.

28. Lee J, Huang M-S, Yang I-C, Lai T-C, Wang J-L, Pang VF, Hsiao $\mathrm{M}$ and Kuo MY: Essential roles of caspases and their upstream regulators in rotenone-induced apoptosis. Biochem Biophys Res Commun. (2008) 371(1): 33-38.

29. Borrie SC, Duggan J and Cordeiro MF: Retinal cell apoptosis. Expert Rev Ophthalmol. (2009) 4(1): 27-45.

30. Chen H-J and Ma Z-Z: N-cadherin expression in a rat model of retinal detachment and reattachment. Invest Ophthalmol Visual Sci. (2007) 48(4): 1832-1838.

31. Radice GL. N-cadherin-mediated adhesion and signaling from development to disease: Lessons from mice. Progress in molecular biology and translational science. Vol.116, Elsevier. Academic Pre ss. (2013)pp: 263-289.

32. Normando EM, Davis BM, De Groef L, Nizari S, Turner LA, Ravindran N, Pahlitzsch M, Brenton J, Malaguarnera G and Guo L: The retina as an early biomarker of neurodegeneration in a rotenoneinduced model of Parkinson's disease: evidence for a neuroprotective effect of rosiglitazone in the eye and brain. Acta Neuropathol Com. (2016) 4(1): 86. 
33. Kohara $T$, Umemoto $T$, Sasaoka $M$, Ota $T$ and Kageyama M: Rotenone Induces Degeneration of Retinal Ganglion Cells and Amacrine Cells in the Rat Retina via Oxidative Stress and Glutamate Excitotoxicity. Invest Ophthalmol Visual Sci. (2011) 52(14): 1365-1365.

34. Matschke V, Theiss $\mathrm{C}$ and Matschke J: Oxidative stress: the lowest common denominator of multiple diseases. Neural Regen Res. (2019) 14(2): 238.

35. Kojima H, Otani A, Oishi A, Makiyama Y, Nakagawa $\mathrm{S}$ and Yoshimura N: Granulocyte colony-stimulating factor attenuates oxidative stress-induced apoptosis in vascular endothelial cells and exhibits functional and morphologic protective effect in oxygen-induced retinopathy. Blood. (2011) 117(3): 1091-1100.

36. Oishi A, Otani A, Sasahara M, Kojima H, Nakamura $\mathrm{H}$, Yodoi $\mathrm{Y}$ and Yoshimura N: Granulocyte colony-stimulating factor protects retinal photoreceptor cells against light-induced damage. Invest Ophthalmol Visual Sci. (2008) 49(12): 5629-5635.

37. van Raam BJ, Drewniak A, Groenewold V, van den Berg TK and Kuijpers TW: Granulocyte colony-stimulating factor delays neutrophil apoptosis by inhibition of calpains upstream of caspase-3. Blood. (2008) 112(5): 2046-2054. 


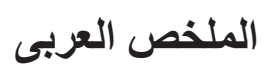

\title{
التأثير المحسّن المحتمل لعامل تحفيز المستعمرة المحبية على التغيرات المستحثة بالروتينون في المستقبلات الضوئية الشبكية للجرذان: دراسة هستولوجية وهستوكيميائية مناعية
}

\author{
سماح قنديل'، محمد بلحه'، ريمون سمير إسطفانوس"
}

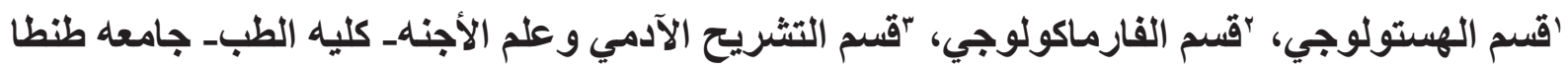

المقدمة: روتينون هو إيزوفلافون عديم الر ائحة يستخدم كمبيد حشري ومبيد للآفات. و هو مثبط قوي لمركب السلسلة

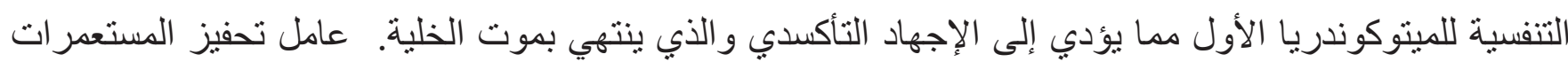
المحببة هو سيتوكين بروتين سكري ويعتبر عامل لنمو مكونات الدم و الذي تتنجه العديد من الخلايا. فهو يعزز إنتشار

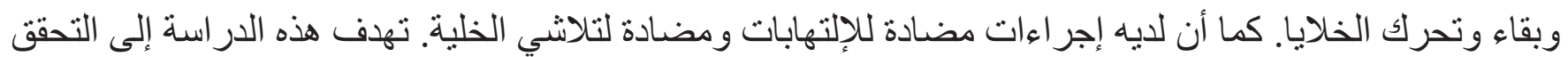
من التأثير المحسّن لعامل تحفيز المستعمر ات المحبية في نموذج الجرذان لتغير ات المستقبلات الضونئية الثبكية التي يسبيها الروتينون.

المواد والطرق: تم إستخدام هب ذكرمن جرذان ويستار وتقسيمها إلى ب مجموعات: المجموعة الضابطة؛ مجموعة

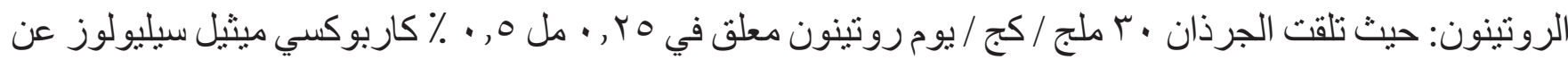

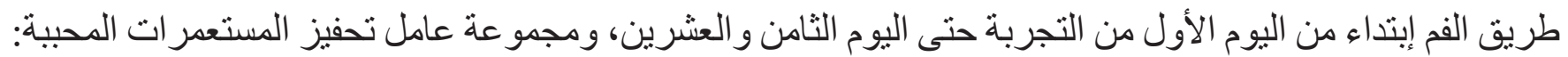

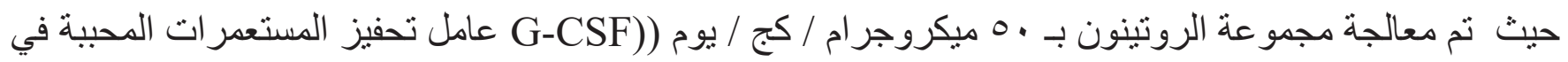

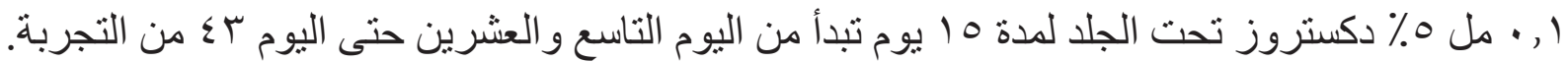

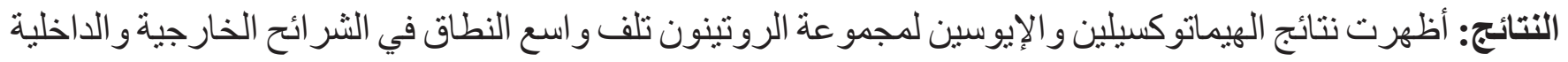
، وتفتت في الأنوية ، كذلك مع إختفاء للأنوية، تكوين فجوات قي المنطقة المتشابكة ، وزيادة هستوكيميائية مناعية

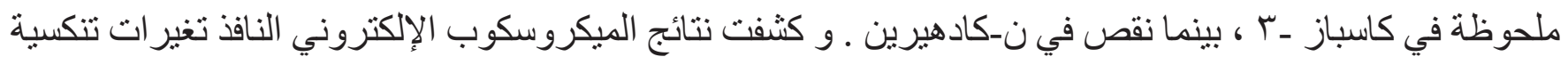

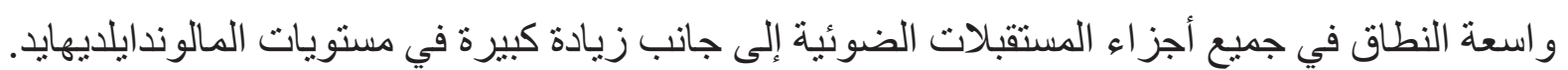

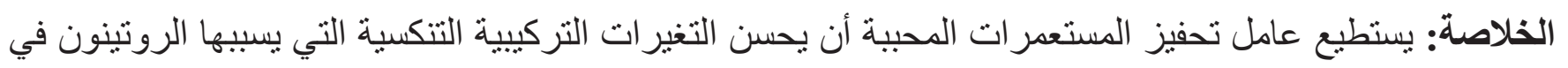

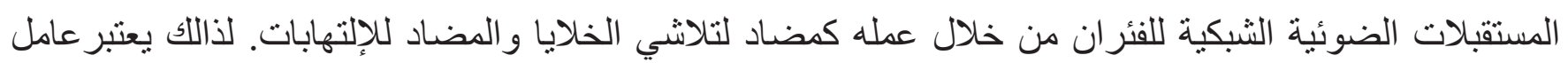
تحفيز المستعمر ات المحببة دواء عصبي و اعد لأمر اض و / أو إصلهابة إصنات الثبكية. 